\title{
GLOBALIZACIÓN, VALORES SOCIALES Y CHOQUE DE CIVILIZACIONES*
}

\author{
GLOBALIZATION, SOCIAL VALUES \\ AND THE CLASH OF CIVILIZATIONS
}

MANUEL GARCÍA FERRANDO

Universidad de Valencia

\author{
PALABRAS CLAVE ADICIONALES \\ ADDITIONAL KEYWORDS \\ Culturas islámica y occidental, Igualdad de género \\ y liberación sexual, Valores democráticos, Teo- \\ rema de Thomas, Teorías de la modernización. \\ Democratic Values, Gender Equality and Sexual \\ , Liberation, Islamic and Western Cultures, Moder- \\ nization Theories, Thomas Theorem.
}

RESUMEN. De las numerosas ideas y variados temas que Huntington desarrolla en su conocida obra El Choque de Civilizaciones y la Reconfiguración del Orden Mundial, la tesis de la pretendida oposición entre la civilización islámica y la cristiano occidental es, con mucho, la que más ha trascendido al ámbito del debate político y de la opinión pública, sobre todo y de manera preocupante, a partir de los actos terroristas de Septiembre de 2001. La utilización de los resultados que ofrece la Encuesta Mundial de Valores, dirigida por Inglehart en los años 2000-2001, permite someter a prueba la tesis de las diferencias culturales entre una muestra amplia de países cristiano occidentales y de países islámicos. Como se pone de manifiesto en el presente artículo, los resultados obtenidos en el análisis comparativo llevado a cabo permiten concluir que, en efecto, existen importantes diferencias culturales entre ambos grupos de países, aunque de tales diferencias no se deriva, necesariamente, un choque de civilizaciones.

ABSTRACT. The thesis of the supposed clash of the Islamic and the western civilizations is, by far, the most diffused and debated of all the subjects and proposals dealt Huntington in his book The Clash of Civilizations and the Remaking of World Order, above all after the terrorist attacks of the September $11^{\text {th }}$. The results of the World Social Survey 2000-2001 directed by Inglehart, are used in the present article to test the thesis of the cultural differences in a wide sample of Western Christian and Islamic societies. The comparative analysis undertaken allows to conclude that the cultural differences between both group societies are quite important, although the existence of such differences do not lead necessarily to a clash of civilizations.

* El presente trabajo es un desarrollo de la lección magistral leída en el acto de apertura del curso 2004-2005 en la Universidad de Valencia (García Ferrando, 2004).

E-mail: Manuel.García-Ferrando@uv.es

Revista Internacional de Sociología (RIS)

Tercera Época, No 42, Septiembre-Diciembre, 2005, pp. 127-150 


\section{INTRODUCCIÓN}

La globalización es un rasgo de la realidad actual que comporta un proceso de trayectorias controvertidas (Martínez González-Tablas, 2000:47), de ahí que el debate sobre los problemas y ventajas que le acompañan se encuentre, en buena medida, polarizado entre dos posturas que parecen por ahora irreconciliables (Beck, 1998a; Dollfus, 1999; Giddens, 2000; Held et al., 2000).

Pero si se analizan con más detalle las reflexiones en las que participan globalistas y escépticos, se puede constatar que hay determinados aspectos en los que coinciden ambos, tales como el reconocimiento de la interconectividad regional, el impacto de la competencia global sobre las viejas jerarquías, los problemas transnacionales y transfronterizos, la expansión de la gobernabilidad internacional y la necesidad de buscar nuevas formas de pensar la política, la economía y el cambio cultural (Ribas, 2002: 43).

Es en este último aspecto en el que cabe inscribir la conocida y debatida tesis del profesor de Harvard Samuel P. Huntington, en el sentido de que el conflicto mundial del futuro estará determinado por un choque de civilizaciones más que por otras causas como las ambiciones territoriales o el capitalismo. Esta tesis fue inicialmente expuesta en un artículo aparecido en la influyente revista Foreign Affairs en 1993 bajo el título "The Clash of Civilizations?", no tanto como afirmación, sino más bien como una interrogación. Se trata de un artículo que provocó de inmediato un fuerte debate y reacciones ciertamente controvertidas, siendo evidente que la tesis había tocado una fibra sensible en muchas personas de todas las civilizaciones.

Con el fin de ofrecer una respuesta más completa, profunda y minuiciosamente documentada a la pregunta del artículo, Huntington redactó posteriormente un libro, con el mismo título, pero sin el interrogante, y con el añadido de "y la reconstrucción del orden mundial" (Huntington, 1997). A lo largo de sus densas páginas y abrumadora colección de referencias bibliográficas y documentales, Huntington explica con detalle, clarifica, complementa y, algunas veces, modifica los temas expuestos en el controvertido artículo, al tiempo que desarrolla nuevas ideas y temas no tratados anteriormente, tales como el concepto de civilización, la existencia o no de una civilización universal, la relación entre poder y cultura, el cambiante equilibrio de poder entre las civilizaciones, la indigenización cultural en las sociedades no occidentales, la estructura política de las civilizaciones, los conflictos generados por el universalismo occidental, el proselitismo musulmán, la autoafirmación china y el aumento del poder chino, las causas y la dinámica de las guerras de línea de fracturas, el futuro de Occidente y de un mundo de civilizaciones, y el impacto decisivo del crecimiento demográfico en la inestabilidad y el equilibrio del poder (Huntington, 1997: 13).

Como puede observarse, se trata de un amplio temario del que prácticamente sólo ha saltado al ámbito del debate político y de la opinión pública la pretendida 
oposición entre la civilización islámica y la cristiano-occidental, esto es, el Islam frente a Occidente. Pero es a partir del ataque terrorista del 11 de Septiembre de 2001 a las torres gemelas de Nueva York y al Pentágono, cuando la tesis, simplificada y popularizada, de Huntington del choque de civilizaciones cobra una actualidad que desborda su ámbito intelectual y académico de debate, y pasa a convertirse para algunos en una evidente explicación de la vinculación del mundo islámico con el terrorismo internacional. Por eso, en su intervención dos meses más tarde ante Naciones Unidas, el presidente Bush atribuye los ataques del 11-S al terrorismo y a la violencia ilegítima, y señala que "la civilización misma, nuestra civilización común, está amenazada" (El Mundo, 11 Noviembre 2001).

Parece evidente que la civilización de la que habla el presidente Bush se refiere a lo que Huntington denomina civilización occidental, y que el terrorismo y la amenaza que comporta se enmarcan en el ámbito de la civilización islámica. Pero desde una rigurosa perspectiva sociológica cabe preguntarse, como sugiere López Pintor (2002: 230), si efectivamente los sistemas de valores y los estilos de vida del mundo islámico son tan singulares como para acabar enfrentándose radicalmente a los del mundo occidental en su conjunto y a los del resto del mundo no islámico, hasta el punto de llegar a hacer pensar en un choque de civilizaciones ${ }^{1}$.

Tratando de dar una respuesta fundamentada a esta pregunta, vamos a tratar en las páginas que siguen, y desde un enfoque estrictamente sociológico, de aportar algún tipo de evidencia empírica y de interpretación teórica que nos ayuden a reflexionar con rigor sobre unos acontecimientos ciertamente conflictivos y preocupantes como los anteriormente referidos del 11-S, o los más recientes del 11 de Marzo de 2004 en Madrid.

Conviene no olvidar que el propio Huntington, en el prefacio del libro que venimos comentando, reconoce que no es, ni pretende ser, una obra de ciencias sociales (Huntington, 1997: 14). Se trata, según su autor, de una interpretación de la evolución de la política global tras la guerra fría, que aspira a ofrecer una estructura, un paradigma, para ver la política global, que sea válido para los estudiosos y útil para las decisiones políticas.

$\mathrm{Al}$ tratarse, pues, de un texto discursivo que va seleccionando aquellas piezas de la realidad que mejor se ajustan a las tesis previamente anunciada y que, en todo caso, son interpretadas de manera que refuercen su argumentación, el libro dista mucho, en efecto, de ser un tratado de ciencias sociales. Y ésa es, en

\footnotetext{
'Este texto de Rafael López Pintor es su contribución al debate que con el título "¿Hay choque de civilizaciones?" publicó la REIS en su n 97, Enero-Marzo 2002, debate al que también aportaron sus contribuciones Salustiano del Campo (Una nueva forma de conflicto), Juan E. Iranzo y Gregorio Izquierdo (La Economia politica del encuentro entre el Mundo Islámico y el Occidental) y José Enrique Rodríguez Ibáñez (Preguntas sobre preguntas). Con diferentes matices, todos los participantes en el debate rechazaron la tesis de Huntington.
} 
RIS

REVISTA INTERNACIONAL DE SOCIOLOGÍA

№ 42, SEPTIEMBRE-DICIEMBRE, 2005

MANUEL GARCÍA FERRANDO

nuestra opinión, una de las mayores limitaciones de la obra de Huntington, ya que se adentra en el tratamiento de temas muy sensibles para toda la humanidad, sin el necesario rigor que sería deseable tener con el fin de no confundir más los debates y conflictos que se suceden continuamente en este "mundo desbocado", por utilizar el expresivo título de un ensayo de Giddens (2000).

Siendo consecuentes con este último deseo, examinaremos en las páginas que siguen la evidencia empírica que ofrece la última Encuesta Mundial de Valores, ya que por la diversidad de países que vienen participando en ella ( 75 sociedades de todo el mundo en la encuesta llevada a cabo en el año 2000) podemos comparar, con el rigor que proporciona el dato empírico, el sistema de valores tanto de sociedades islámicas como occidentales, así como del resto de civilizaciones a las que se refiere Huntington en su propuesta de paradigma civilizatorio para comprender el cambio social en el ámbito de las relaciones internacionales surgidas después de la caída del muro de Berlín.

\section{LA REFLEXIÓN SOCIOLÓGICA GLOBAL Y LA ENCUESTA MUNDIAL DE VALORES}

Desde sus orígenes, la sociología ha hecho manifestación de sus ambiciones universalizadoras de convertirse en la ciencia de la sociedad, entendida ésta como la colectividad de seres humanos que viven y actúan con relaciones interdependientes (García Ferrando, 1999).

Si bien es cierto que el origen europeo de los fundadores de la sociología, desde Comte a Weber, pasando por Spencer, Marx y Durkheim, no impidió a éstos interesarse por otras sociedades y culturas distintas de las europeas (Sanguineti, 1977; Lucas Marín, 1986; García Ferrando, 1999; Zeitlin, 1968), no es menos cierto que desde aproximadamente la segunda década del siglo XX hasta el final de la Segunda Guerra Mundial, la disciplina tuvo grandes dificultades para expandirse más allá de las sociedades industriales occidentales en las que había nacido, y la sociología comparativa fue perdiendo empuje en Europa y en los Estados Unidos. Como han señalado recientemente R. Cohen y P. Kennedy, esta falta de interés por las investigaciones internacionales probablemente tenga que ver con el desarrollo de los intensos sentimientos nacionalistas, tan presentes en las causas que condujeron al estallido de las dos guerras mundiales y al intento de crear Estados nacionales modernos, poderosos y exclusivos (Cohen y Kennedy, 2000).

Pero con el final de la Segunda Guerra Mundial se estableció una nueva distribución de las fuerzas internacionales. Los viejos imperios europeos desaparecieron, y aparecieron nuevos Estados nacionales en el escenario mundial. El nuevo orden internacional condujo al establecimiento de nuevas áreas de estudio en las principales universidades europeas y norteamericanas, dedicadas 
a la investigación de las diversas sociedades y culturas no occidentales, al tiempo que la sociología comenzaba también a establecerse en universidades de estos últimos países (Cardoso y Falleto, 1969).

En el proceso de internacionalización de las sociologías nacionales europeas y norteamericana resulta decisiva la influencia de este último país, como destaca J. Picó en su trabajo sobre lo que denomina "los años dorados de la sociología" que transcurren entre 1945 y 1975 (Picó, 2003). El apoyo económico y la expansión de las técnicas de investigación que impulsó Estados Unidos, la adopción del inglés como lengua oficial de comunicación académica y profesional, y la internacionalización de programas, proyectos y comunicaciones forjaron un terreno común de problemas e intereses entre ambos continentes (Picó, 2003: 18) que, en buena medida, influyó también en el desarrollo de la sociología en el resto de los países del mundo.

La gran diversidad de ritmos y procesos de desarrollo que emergen tanto en los países más desarrollados como en los que lo están menos (los más numerosos, que configuran las grandes áreas subdesarrolladas del mundo) conduce a que los sociólogos se aperciban, especialmente en las dos últimas décadas del siglo XX, de lo difícil que resulta aislar a un país y afirmar que todas las gentes que allí viven conforman una sociedad única, ya que cada vez resulta más difícil establecer con claridad las diferencias entre lo "interno" y lo "externo".

Aunque es el sociólogo B. Moore el que en un anticipatorio artículo acuña el término "sociología global" para referirse a la necesidad de estudiar globalmente la sociedad mundial (Moore, 1966), es probablemente Immanuel Wallerstein (1974) el que ofrece una respuesta más atrevida e importante a este problema. Al presentar su noción de un sistema mundo, Wallerstein propone la idea de abandonar el Estado o la sociedad nacional como unidad de análisis, ya que ambos no son en realidad un sistema social en tanto que lo que necesitamos para seguir avanzando en la comprensión del cambio social es hablar de sistemas sociales. Y el único sistema social en el presente proceso civilizatorio es el sistema mundo (Wallerstein, 1974: 51).

Esta declaración simboliza lo que un número creciente de sociólogos estaban descubriendo en su estudio del cambio social en las últimas décadas del siglo $\mathrm{XX}$ : que era necesario tratar de pensar globalmente, pues aunque los sistemas sociales pueden variar considerablemente de un lugar a otro, existen procesos y transformaciones más amplias que operan a nivel global e impactan de un modo u otro a todo el mundo (Tortosa, 1997: 103-106).

Pero a diferencia de lo que ocurre en el campo de la economía, donde la creciente acumulación de datos económicos por parte de las cada vez más poderosas instituciones internacionales, tales como el Banco Mundial, el Fondo Monetario Internacional, la FAO y los servicios estadísticos y de estudio de las Naciones Unidas, van haciendo más accesible a los economistas el estudio desde una perspectiva global y económica del sistema mundo, no ocurre lo mismo en el campo 
RIS

REVISTA INTERNACIONAL DE SOCIOLOCIA

№ 42, SEPTIEMBRE-DICIEMBRE, 2005

MANUEL GARCÍA FERRANDO

de la sociología, debido a su propio y difícilmente acotable campo de estudio. Las fuentes de datos sociológicos continúan teniendo en los años 60,70 y 80 del pasado siglo un alcance nacional o regional, y no resulta fácil realiza comparaciones internacionales ante la ausencia de un organismo que pudiera asumir el ordenamiento de datos sociológicos a escala mundial.

Es bien cierto que a lo largo de estas décadas se van acumulando numerosos datos provenientes de las encuestas llevadas a cabo en muchos países, particularmente en temas relacionados con los valores sociales. Se trata de un campo privilegiado de estudio que permite conocer, entre otras cosas, las visiones del mundo que tiene la gente, su definición de lo deseable y de lo rechazable, así como la evaluación que realizan del acelerado cambio social que va teniendo lugar en la mayor parte del mundo.

Es en este ámbito de estudio en el que el sociólogo de la Universidad de Michigan, R. Inglehart, inicia un trabajo de comparación de los resultados de diversas encuestas sobre valores sociales llevadas a cabo en unos pocos países occidentales, trabajo recogido en su influyente libro La revolución silenciosa, publicado en 1977. En este libro, que rápidamente se difunde en los medios académicos de muchos países, y no sólo occidentales, Inglehart desarrolla su tesis de que los valores de las poblaciones occidentales se estaban desplazando "desde un énfasis abrumador sobre el bienestar material y la seguridad física, hacia un énfasis mucho mayor en la calidad de vida" (Inglehart, 1977: 3). En síntesis, la revolución silenciosa consistía en un proceso de mudanza, mediante el cambio intergeneracional, desde una cultura materialista a otra posmaterialista.

El interés que despierta el trabajo de Inglehart conduce a partir de los años ochenta a que un número creciente de países se sume a su proyecto de investigación (Inglehart, 1991; Díez Nicolás e Inglehart, 1994). De este modo, se han venido realizando en los últimos años del siglo XX diversas oleadas de la Encuesta Mundial de Valores, en la que han participado 75 países en la encuesta de los años 2000 y 2001 . Al pertenecer estos países a los cinco continentes, sus resultados están permitiendo conocer el alcance del cambio social que Inglehart denomina posmodernización, y que incluye como una de sus dimensiones principales el posmaterialismo (Inglehart, 2003).

Es de destacar que en su caracterización del giro posmoderno, Inglehart, en relativa sintonía con los planteamientos de Giddens (1995) y Beck (1998b), no habla tanto de ruptura, como de un viraje. Con ello, subraya la persistencia de dimensiones modernas, tales como la secularización, la individualización y la especialización, que, viniendo de atrás, perduran y se radicalizan en esta reciente etapa de la sociedad industrial avanzada. Los cambios, que afectan a numerosas dimensiones de la vida y a una amplia variedad de normas sociales, conforman un síndrome congruente en el que el posmaterialismo se encuentra mejor y más empíricamente determinado. Sin embargo, y éste es un argumento que interesa sobremanera a la tesis del choque de civilizaciones y a la hipotética oposición entre el Islam y el Occidente cristiano 
secularizado, el posmaterialismo ya no sería el componente más importante de la posmodernización, puesto que "los cambios en los roles de género y en las actitudes hacia los gays y las lesbianas han sido más sobresalientes" (Inglehart, 1998: 4), y porque ésta entraña, en su núcleo, una disminución de la importancia concedida a todo tipo de autoridad (Inglehart, 1998: 51).

A comienzos del siglo XXI, la base de datos que contiene los resultados de todo este ingente trabajo de investigación empírica se ha convertido, probablemente, en uno de los mejores instrumentos para desarrollar un programa de investigación sociológica auténticamente global que permita la elaboración de modelos teóricos fundamentados (grounded theory) adaptados a diferentes dimensiones del sistema social. En particular, dicha base de datos contiene información empírica con la que poder contrastar la propuesta de Huntington de utilizar el punto de vista de las civilizaciones para entender lo que está pasando en el mundo en el presente periodo histórico.

\section{EL PARADIGMA CIVILIZATORIO Y LAS DIFERENCIAS ENTRE CIVILIZACIONES}

No resulta demasiado arriesgado afirmar que Inglehart y el resto de sociólogos que venimos participando en el desarrollo de la Encuesta Mundial de Valores (García Ferrando y Ariño, 1999 y 2001) estamos de acuerdo, a grandes rasgos, con la noción en la que fundamenta Huntington su tesis del choque de civilizaciones: que en el mundo posterior a la guerra fría, las distinciones más importantes entre los pueblos no son ideológicas, políticas ni económicas; son culturales (Huntington, 1997: 21-23).

En efecto, es fácil compartir con Inglehart su idea de que tanto las personas consideradas individualmente, como las grandes colectividades sociales, se esfuerzan por responder en la actualidad a la pregunta más básica que los seres humanos pueden afrontar: ¿quiénes somos? Y la responden, argumenta Huntington, en la forma tradicional en que la humanidad lo ha hecho, haciendo referencia a las cosas que más importan a los seres humanos. "La gente se define desde el punto de vista de la genealogía, la religión, la lengua, la historia, los valores, costumbres e instituciones. Se identifican con grupos culturales: tribus, grupos étnicos, comunidades religiosas, naciones y, en el nivel más alto, civilizaciones. La gente usa la política no sólo para promover sus intereses, sino también para definir su identidad. Sabemos quiénes somos sólo cuando sabemos quiénes no somos, y con frecuencia sólo cuando sabemos contra quiénes estamos" (Huntington, op.cit.). Para Huntington, los Estados nación continuarán siendo los actores principales en los asuntos mundiales y su conducta estará determinada, por una parte, al igual que en el pasado, por la búsqueda de poder y riqueza, pero por otra, también por preferencias, coincidencias y diferencias culturales. Pero, a diferencia de lo que 
ocurría con los tres agrupamientos más importantes de Estados durante la guerra fría (Estados Unidos, Unión Soviética y países neutrales), con el desplome del mundo comunista el sistema internacional de la Guerra Fría ha pasado a ser historia, y en el nuevo mundo multipolar y multicivilizacional que lo ha sustituido, los agrupamientos de los Estados se vienen realizando alrededor de las civilizaciones principales del mundo, a saber: la occidental, la latinoamericana, la africana, la islámica, la sinoconfuciana, la hindú, la ortodoxa, la budista y la japonesa (Huntington, 1997: 29-32).

Según Huntington, si vemos el mundo desde este paradigma civilizatorio, se pueden evitar muchas de las dificultades que presentan otros paradigmas como el del fin de la historia (Fukuyama, 1989) o el de la división del mundo entre países ricos y países pobres, esto es, entre Norte y Sur. Además, considera que buena parte de los hechos importantes ocurridos en el mundo tras la Guerra Fría son compatibles con el paradigma civilizatorio que propone y podrían haber sido predichos desde él. Por ejemplo, la desintegración de la Unión Soviética y Yugoslavia, las guerras en curso en sus antiguos territorios, el aumento del fundamentalismo religioso por todo el mundo, la resistencia de los Estados islámicos a la presión occidental sobre Irak y Libia, los esfuerzos de los Estados islámicos y confucianos por adquirir armas nucleares y plataformas de lanzamiento, el papel continuado de China como gran potencia, o la consolidación de nuevos regímenes democráticos en unos países y no en otros (Huntington, 1997: 40).

Como tema de ensayismo sobre política internacional, la propuesta de este profesor de Harvard puede ser sugerente. Pero, desde un punto de vista científico social, dista mucho de ofrecer pruebas realmente empíricas relacionadas con un sólido modelo teórico como para que pueda ser admitida sin mayor discusión. Por otro lado, sus afirmaciones de que la revitalización de la religión que cree percibir en gran parte del mundo está reforzando las diferencias culturales, y de que la cultura islámica explica en buena medida la incapacidad de la democracia para abrirse paso en buena parte del mundo musulmán, pueden estar contribuyendo a crear un confuso y negativo clima de opinión, en lugar de inspirar iniciativas políticas realmente pacificadoras, de las que tan necesitado está el mundo.

Por todo ello, vamos a someter a prueba la tesis del choque de civilizaciones utilizando como material de análisis los resultados de la última oleada de la Encuesta Mundial de Valores (E.M.V.), tal como han hecho recientemente Inglehart y sus colaboradores (Inglehart, 2003) ${ }^{2}$. De este modo, pretendemos acotar lo

\footnotetext{
${ }^{2}$ En este libro, del que Inglehart es editor, se recogen diversas aportaciones de sociólogos que, en sus respectivos países, han participado en la Encuesta Mundial de Valores 2000-2001. Es de destacar el capítulo del que es autor Juan Díez Nicolás, director de la encuesta española, y que en su aportación utiliza datos del conjunto de resultados de la EMV para refutar la tesis de Huntington, así como la tesis del Fin de la Historia de Fukuyama (Díez Nicolás, 2003).
} 
que tenga de ideológico dicha tesis, así como su posible capacidad para explicar esa parte de la realidad social que hacen más accesibles los estudios mediante encuesta.

\section{Las diferencias entre el Islam y Occidente}

En el debate sobre la tesis de Huntington, es evidente que el propio concepto de "civilización" es crucial si se desea realmente someter a prueba dicha tesis. Sin embargo, son muchos los autores que han señalado que, en su formulación, Huntington no ofrece una definición clara, ya que siempre se refiere a civilización en términos generales $\mathrm{y}$, lo que es más grave para el correcto contraste de su contenido, utiliza de forma intercambiable los conceptos de civilización y cultura (Russet et al., 2000).

Aunque Huntington reconoce que resulta difícil detallar los valores, normas, instituciones y formas de pensar de una sociedad que se encuentran en la base de su civilización, no parece tener duda alguna en que, de todos los elementos objetivos que definen las civilizaciones, el más importante es la religión. En consecuencia, "la religión es la característica definidora central de las civilizaciones" (Huntington, 1997: 47).

Por todo ello, si se desea contrastar la tesis de Huntington, la religión será la variable independiente crucial. Dicho de otra manera, y de acuerdo con la exposición de Norris e Inglehart (2002), los valores, normas, instituciones y formas de pensar deberán depender, en buena medida, de la fe y de la filiación religiosa. Conviene recordar también que la religión es la clave de la clasificación de las civilizaciones que propone Huntington y que, referidas al mundo contemporáneo, son las siguientes: Cristiana Occidental, Ortodoxa, Sino/Confuciana, Japonesa, Hindú, Islámica, Latinoamericana y, posiblemente, Africana.

Siguiendo la argumentación de Norris e Inglehart (2002: 235-237), podemos formular las siguientes hipótesis a partir de las nociones de cultura y civilización de Huntington:

$\mathrm{H}_{1}$ : Las sociedades que pertenezcan a una civilización determinada deben diferenciarse de forma significativa de las sociedades pertenecientes a otra civilización, en lo que se refiere a sus valores, normas, etc.

$\mathrm{H}_{2}$ : Dentro de cada civilización, la varianza estadística de los valores debe ser más pequeña que la correspondiente varianza entre civilizaciones diferentes.

$\mathrm{H}_{3}$ : Dentro de una sociedad dada, los grupos pertenecientes a una determinada religión deberán presentar diferencias significativas con respecto a los grupos pertenecientes a otras religiones.

$\mathrm{H}_{4}$ : Dentro de una sociedad dada, la varianza de la distribución de los valores culturales de un grupo deberá ser más pequeña que la correspondiente varianza entre grupos diferentes. 
RIS

Es evidente, como señala Esmer (2003: 38), que habría que dar un enorme salto para concluir que de las diferencias entre civilizaciones formuladas en estas cuatro hipótesis pueda, producirse un "choque". Sin embargo, si nos ajustamos a la teoría, como mínimo se podrá demostrar que, en efecto, existen dichas diferencias, y que la clasificación de culturas a partir de la variable religión es plausible.

Aunque es enorme el volumen de literatura dedicada, desde diferentes perspectivas científico-sociales, al estudio de las dimensiones de las culturas y civilizaciones, en línea con la exposición y argumentación que venimos realizando vamos a seguir el análisis estadístico llevado a cabo recientemente por Inglehart y Norris (2002) en su estudio comparativo de las 75 sociedades que han participado en la Encuesta Mundial de Valores de 2000 y 2001. Dicho brevemente, la perspectiva seguida por ambos autores ha consistido en codificar a todas las personas que viven en una sociedad como pertenecientes a la misma civilización (determinada por la religión dominante en cada sociedad), para seguidamente comparar a los individuos que viven en sociedades predominantemente islámicas con aquellos otros que viven en sociedades cristiano-occidentales, así como con los residentes en el resto de sociedades, esto es, ortodoxas, latinoamericanas, centroeuropeas, sin-confucianas, subsaharianas, hindúes y japonesa.

A efectos de parsimonia científica, la comparación se ha llevado a cabo tan sólo en dos dimensiones altamente significativas para el tema que nos ocupa: una escala de valores políticos democráticos (aprobación del funcionamiento de la democracia, ideales democráticos, aprobación o rechazo de líderes religiosos, aprobación o rechazo de líderes fuertes), y una segunda escala de valores sociales liberales (aprobación de la igualdad de género, del divorcio, de la homosexualidad y del aborto). En las Tablas 1 y 2 se presentan resumidos los valores medios de ambas escalas en los tres agrupamientos de sociedades señaladas.

Tal como puede observarse en los resultados de la Tabla 1, las sociedades cristiano-occidentales y las islámicas presentan valores similares en las medias de tres de los componentes de la escala de valores político-democráticos, a saber: aprobación del funcionamiento de la democracia, aprobación de los ideales democráticos y rechazo de líderes (gobiernos) fuertes. Además, en estas tres dimensiones las sociedades islámicas superan al resto de las sociedades en su apoyo a la democracia.

En la única dimensión en la que las sociedades islámicas puntúan significativamente por debajo de las sociedades occidentales y del resto de sociedades es en el "grado de rechazo a líderes religiosos", que es mucho menor en las sociedades islámicas que en cualquier otro tipo de sociedad. Es una manifestación más de la importancia de la religión en este tipo de sociedades.

La Tabla 2 presenta unos resultados bien diferentes a los anteriores por lo que respecta a la comparación de las sociedades occidentales con las islámicas. En las cuatro dimensiones de la escala de valores sociales liberales, esto es, en el grado de aprobación de la igualdad de género, de la homosexualidad, del aborto 
Tabla 1.

Valores medios de la escala de valores politicos en sociedades cristiano-occidentales, islámicas y resto de sociedades

\begin{tabular}{|l|c|c|c|c|}
\hline & \multicolumn{3}{|c|}{ Valores Político-Democráticos } \\
\hline Tipo de sociedad & $\begin{array}{c}\text { Aprueba } \\
\text { funcionamiento } \\
\text { democracia }\end{array}$ & $\begin{array}{c}\text { Aprueba } \\
\text { ideales } \\
\text { democráticos }\end{array}$ & $\begin{array}{c}\text { Desaprueba } \\
\text { líderes } \\
\text { religiosos }\end{array}$ & $\begin{array}{c}\text { Desaprueba } \\
\text { líderes } \\
\text { fuertes }\end{array}$ \\
\hline Cristiano-Occidental & 68 & 86 & 62 & 61 \\
\hline Islámica & 68 & 87 & 39 & 61 \\
\hline Resto de sociedades & 63 & 80 & 53 & 55 \\
\hline $\begin{array}{l}\text { Diferencia entre todas } \\
\text { las medias de los grupos }\end{array}$ & $.18^{*}$ & $.20 *$ & $.49^{*}$ & $.19^{*}$ \\
\hline $\begin{array}{l}\text { Diferencia entre grupos } \\
\text { Occidentales e islámicos }\end{array}$ & $.02^{*}$ & $.03^{*}$ & $.30^{*}$ & .01 \\
\hline
\end{tabular}

Fuente: Inglehart y Norris, 2002: 254.

Nota. Las escalas van de 0 a 100; los valores de las diferencias de las medias afectados por un asterisco * son significativos al nivel .001 .

Tabla 2.

Valores medios de la escala de valores sociales liberales en sociedades cristiano-occidentales, islámicas y resto de sociedades

\begin{tabular}{|l|c|c|c|c|}
\hline & \multicolumn{4}{|c|}{ Valores Sociales Liberales } \\
\hline Tipo de sociedad & $\begin{array}{c}\text { Aprueba la } \\
\text { igualdad } \\
\text { de género }\end{array}$ & $\begin{array}{c}\text { Aprueba } \\
\text { la } \\
\text { homosexualidad }\end{array}$ & $\begin{array}{c}\text { Aprueba } \\
\text { el } \\
\text { aborto }\end{array}$ & $\begin{array}{c}\text { Aprueba } \\
\text { el } \\
\text { divorcio }\end{array}$ \\
\hline Cristiano-Occidental & 82 & 53 & 48 & 60 \\
\hline Islámica & 55 & 12 & 25 & 35 \\
\hline Resto de sociedades & 67 & 28 & 36 & 47 \\
\hline $\begin{array}{l}\text { Diferencia entre todas } \\
\text { las medias de los grupos }\end{array}$ & $46^{*}$ & $45^{*}$ & $38^{*}$ & $.33^{*}$ \\
\hline $\begin{array}{l}\text { Diferencia entre grupos } \\
\text { occidentales e islámicos }\end{array}$ & $64^{*}$ & $51^{*}$ & $33^{*}$ & $.37^{*}$ \\
\hline
\end{tabular}

Fuente: Inglehart y Norris, 2002: 255.

Nota. Las escalas van de 0 a 100; los valores de las diferencias de las medias afectados de un asterisco

* son significativos al nivel .001 . 
RIS

REVISTA INTERNACIONAL DE SOCIOLOGIA

y del divorcio, los valores obtenidos son significativamente más bajos en las sociedades islámicas que en las sociedades occidentales e, incluso, que en el resto de sociedades.

Es una clara manifestación de la profunda separación que existe entre el Islam y el Occidente en lo que se refiere a tales valores de corte liberal y secular, ya que respecto a estos valores las sociedades islámicas se manifiestan muy tradicionales -tibio apoyo a la igualdad de género, y rechazo generalizado de la homosexualidad, del aborto y del divorcio-, en tanto que las sociedades occidentales se manifiestan cada vez más permisivas y tolerantes en la serie de las Encuestas Mundiales de Valores que se vienen llevando a cabo desde finales de los años ochenta. Y lo que es más importante, los detallados análisis estadísticos llevados a cabo por Inglehart y Norris ponen de manifiesto que las generaciones más jóvenes en las sociedades islámicas continúan manifestándose casi igual de tradicionales que las de sus mayores, a diferencia de lo que ocurre en el Occidente, donde las generaciones más jóvenes se manifiestan cada vez más tolerantes en esta sensible parte de la vida social, asociada a lo que se conoce popularmente con la llamada "revolución sexual" ( Ruiz de Olabuénaga, 1998).

Se puede concluir, pues, que las sociedades islámicas no difieren fundamentalmente de las occidentales en lo que se refiere a los valores políticos de sus respectivas poblaciones. En cambio, las diferencias son significativas en todo aquello relacionado con la "revolución sexual", que está muy lejos de haberse iniciado en las poblaciones islámicas, incluidas sus generaciones más jóvenes.

Es bien cierto que existen ciertas diferencias en el significado de lo que la gente entiende por "democracia", término que suele ir asociado a la prosperidad en muchos países no occidentales. Por ello, la atracción que ejerce la democracia en estas sociedades puede ir más unida a un deseo de mejora del nivel de vida, antes que al logro de la libertad de expresión o de la libertad individual. Sin embargo, el hipotético choque de civilizaciones que enfrenta al Islam con la civilización occidental, como sostiene Huntington, no parece que vaya a producirse siguiendo la línea de fractura de los valores políticos. El enfrentamiento, en todo caso, podría fundamentarse en los valores asociados con la liberalización de costumbres que acompaña a la revolución sexual en los países occidentales. En otras palabras, concluyen Inglehart y Norris (2003: 15), las diferencias culturales entre el Islam y el Occidente son más "una cuestión de eros que de demos".

\section{La coherencia interna de las diferentes civilizaciones}

Las restantes hipótesis que han sido formuladas anteriormente, esto es, la $\mathrm{H}_{2}, \mathrm{H}_{3}$, $\mathrm{y}_{4}$ hacen referencia a la coherencia interna de las civilizaciones, ya que si éstas son realmente agentes determinantes de los valores y formas de pensar de sus respectivas poblaciones, el grado de varianza de tales valores y formas de pensar será siempre menor que la varianza entre poblaciones diferentes. 
Para someter a prueba estas hipótesis, Esmer (2003: 49-54) ha realizado un análisis de varianza (ANOVA) con los valores de las cuatro dimensiones más representativas del sistema de valores en el modelo teórico desarrollado por Inglehart (trabajo y ética protestante, capital social, modernización, cultura democrática), y ha agrupado las sociedades que han participado en la EMV de 2000-2001 según su religión predominante. En la Tabla 3, del amplio número de combinaciones de resultados disponibles, hemos seleccionado los valores de las varianzas de las cuatro dimensiones de valores diferenciando entre sociedades protestantes, católicas, islámicas y ortodoxas. De este modo, se puede comprobar hasta qué punto cada una de estas tres civilizaciones cristianas difiere o no de la civilización islámica, en lo que se refiere a la consistencia interna de sus dimensiones más importantes del sistema de valores.

Tabla 3.

Consistencia de los Valores en cada Civilización (desviaciones estándar)

\begin{tabular}{|l|l|l|l|l|}
\hline Dimensiones & Protestante & Católica & Islámica & Ortodoxa \\
\hline Ética protestante & & & & \\
Trabajo duro & 0.46 & 0.50 & 0.49 & 0.45 \\
\hline Capital Social & & & & \\
Confianza interpersonal & 0.50 & 0.45 & 0.46 & 0.42 \\
& & & & \\
\hline Modernización & 3.29 & 3.13 & 1.59 & 3.10 \\
Importancia de Dios & 1.86 & 2.15 & 2.73 & 2.51 \\
Fatalismo/Libre elección & 1.43 & 1.45 & 0.90 & 1.20 \\
Escala familismo & 1.25 & 1.27 & 1.43 & 1.15 \\
Trabajo de la mujer & 7.69 & 7.34 & 2.67 & 6.00 \\
Tolerancia sexual & & & & \\
\hline Cultura democrática & 1.49 & 1.78 & 1.64 & 1.79 \\
Tolerancia & 1.58 & 1.61 & 1.43 & 1.47 \\
Participación & 1.81 & 1.97 & 1.95 & 2.02 \\
Alternativas democracia & & & & \\
\hline
\end{tabular}

Los resultados de la Tabla 3 pueden resumirse del siguiente modo:

a) En lo que respecta a los valores relacionados con el trabajo y la ética protestante, las desviaciones estándar para las cuatro civilizaciones son muy parecidas, prácticamente iguales.

b) Para todos los indicadores de cultura democrática, las poblaciones de las sociedades islámicas se diferencian de sus medias con la misma probabilidad que en las otras tres poblaciones. 
c) Las variables relacionadas con la confianza interpersonal y el capital social, con la excepción de "firmar una petición", presentan desviaciones estándar aproximadamente similares en los cuatro grupos. La civilización islámica se muestra más consistente con la dimensión de firmar una petición.

d) De manera significativa, la cultura islámica presenta la mayor varianza en las actitudes referentes al trabajo de la mujer fuera del hogar. En apariencia, el mundo islámico se encuentra dividido en este tema.

e) En el caso de las escalas de familia y matrimonio, las poblaciones islámicas presentan una desviación estándar menor que las otras poblaciones.

f) La mayor diferencia de varianza entre la cultura islámica y las otras culturas se manifiesta en la tolerancia sexual. Esta escala presenta una varianza de sólo 2.67 para las poblaciones islámicas, mientras que en las otras tres poblaciones oscila entre 6.00 y 7.69. Se trata de un resultado que adquiere mayor relieve cuando se tienen en cuenta los valores medios de las cuatro escalas:

$\begin{array}{lr}\text { Protestante } & 14.5 \\ \text { Católica } & 11.8 \\ \text { Ortodoxa } & 9.3 \\ \text { Islámica } & 4.3\end{array}$

Si se tiene en cuenta que la escala de tolerancia sexual oscila entre un valor mínimo de 0 y un máximo de 30 , el valor medio que presentan las poblaciones islámicas 4.3 es ciertamente bajo, muy próximo al polo de ninguna tolerancia sexual o valor 0 . Este hecho, acompañado al bajo valor de la desviación estándar, está indicando que, en efecto, nos encontramos ante una civilización bien diferenciada.

g) Las variables sobre religiosidad ofrecen también resultados de interés. Dios es muy importante en las vidas de las poblaciones islámicas, que son más religiosas que el resto. Además, como la desviación estándar es más baja que en las otras tres poblaciones, quiere ello decir que las culturas islámicas son más homogéneas en materia de religiosidad que las de origen cristiano.

Estas conclusiones son consistentes con las que han alcanzado Inglehart y Norris (2002). Dos son los factores más prominentes en la definición de una civilización islámica: una elevada religiosidad y una baja tolerancia sexual. Se trata, además, de unas características en las que las sociedades islámicas se presentan con mayor coherencia y consistencia que las sociedades católicas, ortodoxas y protestantes. Sin embargo, "no parece que se pueda hablar de un área cultural islámica de carácter distintivo en lo que se refiere a valores relacionados con la ética protestante, el capital social o la cultura democrática. Pero sí tiene sentido hablar de una civilización islámica dentro del contexto de la religiosidad, consideración de la mujer y tolerancia sexual" (Esmer, 2003: 54). 


\section{La cultura islámica en sociedades plurales}

La importancia de la religión como elemento caracterizador de una civilización tiene también que manifestarse en las sociedades en las que no existe una sola religión dominante, y que cuentan con dos o más grupos religiosos significativos. Para someter a prueba la validez de la tercera y cuarta hipótesis anteriormente formuladas en dichos términos, Esmer (2003: 55-63) seleccionó para su estudio ocho sociedades que contienen dos o más grupos amplios de población con diferente filiación religiosa: Bulgaria, Macedonia, Bosnia, Montenegro, Nigeria, Uganda e India.

Dentro de este conjunto de sociedades es posible comparar las poblaciones islámicas dentro de un sólo país con protestantes (Nigeria y Uganda), con católicos (Uganda), con hindúes (India) y con poblaciones ortodoxas de Albania, Bosnia, Bulgaria, Macedonia y Montenegro. En todas estas sociedades la población musulmana es autóctona, y no inmigrante como en los países europeos, lo que es ventajoso a efectos de la investigación llevada a cabo. Con todo, hay que reconocer que estos ocho países tienen serias limitaciones en cuanto a la información empírica que presentan. En primer lugar, cinco de ellos están situados en los Balcanes y sólo permiten la comparación con la cultura ortodoxa. En segundo lugar, se trata, en este caso, de una zona en la que los conflictos étnico-religiosos han conducido a guerras abiertas en los últimos años. En tercer lugar, son países con rentas per cápita bajas o muy bajas. Y en último lugar, se trata de países con puntuaciones bastante bajas en las dimensiones seleccionadas del sistema de valores, lo que puede influir en la búsqueda de diferencias culturales.

La evidencia empírica de la que se dispone en lo que se refiere al grado de correlación existente en países occidentales entre filiación religiosa y valores de capital social, ética protestante y otras dimensiones estudiadas anteriormente, apunta, cuando se toma como unidad de análisis al individuos, en la dirección de que hay escasa o nula correlación. Católicos y protestantes en Alemania, Suecia y Estados Unidos, por ejemplo, no presentan diferencias en sus manifestaciones de confianza interpersonal. La razón estriba en que "... una vez establecidas, las diferencias culturales vinculadas a la religión forman parte de la cultura nacional, que es trasmitida a la población de una nación a través de su sistema educativo y de los medios de comunicación. A pesar de la globalización, la nación continúa siendo una unidad clave de experiencias compartidas y de instituciones culturales y educativas que dan forma a los valores de casi todo el mundo en una sociedad" (Inglehart y Baker, 2000: 37).

Partiendo del análisis estadístico llevado a cabo por Esmer $(2003)^{3}$, presenta-

\footnotetext{
${ }^{3}$ No se incluyen por su extensión las tablas resumen del análisis estadístico llevado a cabo por Esmer, ya que superan el espacio disponible para el presente artículo. Por ello, se presentan tan sólo los resultados más relevantes del referido análisis.
} 
RIS

REVISTA INTERNACIONAL DE SOCIOLOGIA

N 42, SEPTIEMBRE-DICIEMBRE, 2005

mos a continuación los principales hallazgos encontrados en los anteriores ocho países de perfil multirreligioso:

a) En la dimensión de trabajo y ética protestante, los indicadores de trabajo duro y frugalidad no manifiestan diferencias apreciables entre los diversos grupos de población dentro de cada país. Sin embargo, los indicadores de perseverancia y determinación son significativamente más bajos entre las poblaciones musulmanas de casi todos los países. Este resultado es congruente con el referido al conjunto de todos los países de la EMV al comparar las poblaciones islámicas con las cristianas. En todos ellos, las sociedades musulmanas puntúan más bajo que el resto de sociedades en ambos indicadores. ¿Quiere esto decir que existe un problema en la cultura islámica relativa a la falta de perseverancia y determinación? La respuesta es afirmativa si seguimos la interpretación de Weber sobre la ética protestante y el desarrollo del capitalismo, y ayudaría a explicar el incierto camino recorrido hasta ahora por la mayor parte de los países musulmanes en el camino del desarrollo capitalista.

b) Los indicadores de capital social no muestran diferencias significativas entre grupos de población musulmana y el resto de poblaciones.

c) Por lo que se refiere a la religiosidad, las poblaciones musulmanas ofrecen las puntuaciones más altas en todos los países estudiados. La pregunta que cabe formularse en el marco de este resultado es hasta qué punto las elevadas proporciones de personas fundamentalistas y dogmáticas en las poblaciones islámicas están relacionadas con la gran importancia que en éstas se concede a la fe religiosa. Los datos disponibles no permiten responder taxativamente, pero la pregunta merece ser explorada en sucesivos estudios.

d) El fatalismo o falta de control en la vida personal se encuentra más extendido de forma significativa entre las poblaciones musulmanas que en el resto de poblaciones.

e) Los resultados referidos a los valores acerca del matrimonio y de la familia no son conclusivos, ya que mientras en algunos países no se aprecian diferencias en las correspondientes escalas, en otros la población musulmana se muestra más conservadora, y en el resto de los países ocurre lo contrario. A diferencia de otras variables, en principio nada hace suponer que el Islam enfatiza más los valores familiares que otras culturas; de ahí que los contextos nacionales influyan más en las pequeñas diferencias observadas que la filiación religiosa.

f) El posicionamiento ante la tolerancia sexual sí discrimina significativamente entre las diferentes filiaciones religiosas en un mismo país. En casi todos los países estudiados, la población musulmana se muestra menos tolerante en materia sexual que las restantes poblaciones, sean éstas católicas, protestantes, ortodoxas o hindúes. Se puede concluir, en consecuencia, que los musulmanes son, por lo general, menos tolerantes en cuestiones relacionadas con "el eros". 
g) Los resultados que tienen que ver con los indicadores de cultura democrática no permiten afirmar que la cultura islámica sea más o menos favorable para un sistema de gobierno democrático. De las 45 comparaciones realizadas con valores democráticos, sólo 15 de ellas han presentado diferencias estadísticamente significativas, aunque es de resaltar que las direcciones que siguen las diferencias encontradas no delimitan una pauta consistente. Por tanto, estos resultados refuerzan la conclusión a la que llegaron Inglehart y Norris en su estudio del conjunto de países de la EMV, en el sentido de que "la línea de fractura básica entre el Occidente y el Islam no concierne a la democracia" (Norris e Inglehart, 2002: 253).

h) Los valores de la desviación estándar de la varianza que se han obtenido, y que ayudan a conocer el grado de consistencia interna de un grupo cultural determinado - cuanto más pequeña sea la desviación estándar, más homogéneo y consistente será el sistema cultural de valores que comparten los miembros del grupo-, ofrecen resultados significativos. Las desviaciones estándar de las poblaciones musulmanas son notablemente más bajas que en el resto de poblaciones por lo que se refiere a las siguientes dimensiones: determinación y perseverancia en los niños, importancia de Dios, escala de religiosidad, escala de secularización, escalas de matrimonio y familia, escala de tolerancia sexual y escala de tolerancia con los vecinos.

De los anteriores resultados cabe concluir, como hace Esmer (op.cit.: 63), que las poblaciones islámicas tienen ciertamente características culturales diferentes a otras poblaciones de filiación religiosa no islámica con las que conviven en un mismo país. La socialización homogeneizadora, consecuente del hecho de vivir en un mismo país, compartiendo, por tanto, el mismo sistema educativo y la influencia del conjunto de los medios de comunicación, no parece haber conseguido que desaparezcan ciertas características culturales propias relacionadas con la religión islámica en los países estudiados.

La lista de características que definen la cultura islámica es muy consistente desde un riguroso punto de vista estadístico. En primer lugar, y de forma destacada, la fe es para los musulmanes muy importante, y superior al grado de importancia que le otorgan las poblaciones que profesan otras religiones.

Otra característica importante de la cultura islámica tiene que ver con la forma que tiene de valorar las cuestiones relacionadas con las mujeres y el sexo. Los valores islámicos dan menor apoyo a la igualdad de género y son menos tolerantes con la liberalización sexual que los valores de otras filiaciones religiosas.

De los diferentes valores relacionados con el trabajo y la ética protestante, las poblaciones musulmanas apoyan el trabajo duro, el ahorro y la frugalidad de forma parecida a como lo hacen otras poblaciones. Sin embargo, apoyan en menor medida y de forma significativa la determinación y la perseverancia.

La cultura política y, más en concreto, los valores democráticos no ofrecen diferencias apreciables entre las poblaciones islámicas, católicas, protestantes, ortodoxas e hindúes. 
Resumiendo todo lo anterior, podemos afirmar, como hace Esmer (op.cit.: 67), que, en el mundo contemporáneo, si se desea definir la civilización islámica, las características básicas y diferenciadoras que conviene observar están relacionadas con la religiosidad, la tolerancia sexual, la perseverancia y la determinación, y el apoyo a la igualdad de género. Por lo tanto, la respuesta que se puede dar, teniendo en cuenta los resultados que ofrecen las diferentes Encuestas Mundiales de Valores, a la pregunta sobre la existencia o no de una civilización islámica es que, en efecto, si existe una civilización islámica.

\section{CONCLUSIONES}

Las controvertidas trayectorias que están siguiendo los cambios que, en las dos o tres últimas décadas, vienen afectando a las diferentes dimensiones sociales, económicas, políticas y culturales que caracterizan a los procesos de globalización, alcanzaron un punto de inflexión con los dramáticos sucesos del 11-S. Los ataques terroristas a las Torres Gemelas de Nueva York y al Pentágono volvieron a dar un fuerte protagonismo al debate que, a lo largo de los años noventa, envolvió a la tesis de Huntington de la posible inevitabilidad de que se produzca un choque de civilizaciones que enfrente al Islam con Occidente y, por extensión, con el resto del mundo. La última frase con la que Huntington finaliza su libro, resume perfectamente su categórico punto de vista: "En la época que está surgiendo, los choques de civilizaciones son la mayor amenaza mundial, y un orden internacional basado en las civilizaciones es la protección más segura contra la guerra mundial" (Huntington, 1997: 386).

Siguiendo una perspectiva sociológica de alcance global, hemos sometido a la prueba de la evidencia empírica la tesis de Huntington, utilizando la ingente masa de información que ofrece la base de datos de las Encuestas Mundiales de Valores que viene coordinando desde los años 80 el profesor Inglehart, de la Universidad de Michigan. La primera y más básica preguntaque hemos tratado de responder es la referente a la existencia o no de una distintiva civilización islámica. La respuesta obtenida al tener en cuenta los resultados de los complejos análisis estadísticos llevados a cabo en la Encuesta Mundial de Valores del año 2000 es que, en efecto, sí existe una civilización islámica, aunque no parece estar caracterizada por la falta de valores políticos democráticos como sostiene Huntington. Las diferencias que presentan las sociedades islámicas con otras sociedades, especialmente con las occidentales, tienen que ver más bien con cuestiones relacionadas con la religiosidad, la igualdad de género, la tolerancia sexual y algunas de las dimensiones que configuran la ética del trabajo, como son la determinación y la perseverancia. 
La pregunta que cabe hacerse ahora, a la vista de la existencia, desde un punto de vista cultural, de una bien diferenciada civilización o cultura islámica, es por qué resulta inevitable que estas características diferenciadoras de las sociedades islámicas conduzcan a un choque de civilizaciones. Desde luego, Huntington no presenta evidencia empirica suficiente que justifique tal inevitabilidad, lo cual no dejaría de ser una polémica más propia de los ámbitos académicos e intelectuales si no fuera porque su tesis ha saltado a las tribunas políticas y a la opinión pública mundial a través de los grandes medios de comunicación.

Tal y como hemos señalado con preocupación, el peligro que acompaña desde el 11-S a las reiteradas referencias que se hacen en determinados ámbitos políticos y mediáticos conservadores a la tesis de Huntington, proviene, como ha señalado oportunamente López Pintor (2002), de que ésta acabe convirtiéndose en una profecía que se cumpla a sí misma tal como anticipa el teorema sociológico de Thomas (Merton, 1964: 419). No deja de ser significativamente sospechosa la proclividad del profesor Huntington y de sus defensores a denunciar amenazas a la civilización occidental, en su versión norteamericana. Ésta se ha puesto de manifiesto una vez más con la publicación reciente de otro controvertido artículo titulado "La amenaza hispánica" (Huntington, 2004a), al que ha seguido el correspondiente libro titulado ¿Quiénes somos? Los desafios a la identidad nacional estadounidense (2004b). En ambos trabajos, Huntington manifiesta su preocupación por la pérdida en los Estados Unidos de los valores centrales de la cultura anglo-protestante como consecuencia de la importante inmigración de población hispánica, esto es, de la proveniente de países latinoamericanos. Según Huntington, el riesgo que se corre con esta inmigración es que, por primera vez en su historia como país de inmigrantes, los Estados Unidos puedan dividirse en dos pueblos con dos culturas diferentes: la angloamericana y la hispánica, y con dos lenguas: el inglés y el español.

Esta pretendida amenaza hispánica ha sido ya denunciada por prestigiosos profesores e investigadores americanos no sólo de origen hispánico, por la demagogia que comporta y por la ignorancia que pone de manifiesto una vez más el hecho de hablar en nombre de toda una entera religión o de una civilización (Klare, 2001).

Volviendo a la amenaza que suponen para Huntington las sociedades islámicas y su escaso éxito con la consolidación de regímenes democráticos y el desarrollo de afluentes economías de mercado, hay que reconocer que, efectivamente, los países islámicos presentan una baja proporción de gobiernos democráticos representativos. Según el informe anual de 2002 que ha preparado la institución Freedom House, de los 192 países que existen en el mundo, aproximadamente dos tercios de ellos (121) son democracias electorales. De los 47 países con mayoría de población islámica, sólo una cuarta parte (11) son democracias electorales. Además, ninguna de las sociedades arábigas de Oriente Próximo y del norte de África son democracias, lo que, a falta de un mayor y mejor análisis, conduce 
a difundir la imagen de que las poblaciones islámicas prefieren antes gobiernos fuertes que gobiernos democráticos.

Una imagen tal, reforzada con la tesis del choque de civilizaciones, parece justificar la política norteamericana de intervencionismo militar en países islámicos con el fin de instalar en ellos regímenes democráticos, al tiempo que da también apoyo a las políticas de control y vigilancia de las minorías islámicas en los países occidentales. Sin embargo, la escalada de conflictos que parece acompañar a la intervención militar de los Estados Unidos en países islámicos contradice la justificación "civilizatoria" de una política tal.

La premio Nobel de la Paz de 2003, la jurista iraní Shirín Ebadí, primera mujer de un país islámico que ha recibido un premio Nobel, viene manifestándose activamente en los últimos tiempos, al igual que otras muchas voces autorizadas, en contra de la teoría del choque de civilizaciones entre el Occidente cristiano y el mundo islámico. En una reciente intervención en el Forum de las Culturas de Barcelona el pasado mes de julio de 2004, Ebadí 'afirmaba que "la democracia tiene que surgir por sí misma desde la sociedad", y que los Estados Unidos deberían haber invertido todo el dinero gastado en la guerra de Irak en estimular los movimientos sociales y el desarrollo de organizaciones cívicas, que es la mejor manera de que surja la democracia en Irak y en otros países islámicos (El País, 3 de julio de 2003).

En este mismo sentido vienen a incidir los informes del Programa de las Naciones Unidas para el Desarrollo Humano (PNUD, 1997 y 2004). En ellos se destaca, entre otras cosas, que el avance de los procesos de globalización está influyendo en que las poblaciones inmigrantes en los países económicamente más desarrollados puedan mantener lazos cada vez más estrechos con sus países de origen gracias al desarrollo de Internet y al abaratamiento de las tarifas aéreas. Este fenómeno obliga, según el PNUD, al cambio de las políticas inmigratorias de los países receptores, los cuales deben promover la conservación de las identidades culturales, así como deberán incrementar el respeto y la representación política de las minorías étnicas y religiosas.

En el prólogo al informe del PNUD de 2004, Mark Brown defiende la libertad cultural como elemento esencial del desarrollo humano e instrumento clave para afianzar la democracia y la estabilidad política. En una época en la que el concepto de choque de civilizaciones resuena con fuerza y de manera inquietante en todo el mundo, "recobra importancia encontrar respuestas a la antigua pregunta de cómo manejar los conflictos en torno al idioma, la religión, la cultura y la etnia" (Prólogo Informe PNUD, 2004). Incluso va más allá este administrador del PNUD en su defensa de las sociedades multiculturales, al afirmar que "la globalización no puede tener éxito a menos que se protejan las libertades culturales". Declaraciones grandilocuentes en un informe, el de PNUD de 2004, que está lleno de buenas intenciones en sus extensas y bien documentadas páginas. Es, como señalaba un reciente editorial del periódico El País dedicado a glosar el informe, "un canto a la tolerancia y a la libertad multicultural" (El País, 16 de julio de 2004); canto al 
que, sin embargo, le faltan posicionamientos concretos ante los problemas reales y candentes que presenta la nueva multiculturalidad en los países desarrollados, como, por ejemplo, el conflictivo tema sobre el uso del velo islámico en las escuelas públicas, especialmente en Francia y otros países europeos. Tema sobre el que no emite juicio alguno el informe del PNUD.

Por todo lo anterior, parece más realista prestar mayor atención al aviso que hace el profesor Huntington, pero con un ánimo opuesto al que ha despertado entre sus más activos exegetas, especialmente la Administración Bush. A-partir del reconocimiento de las diferencias culturales que ponen de manifiesto las Encuestas Mundiales de Valores, diferencias que se encuentran próximas a las experiencias de vida cotidiana de muchos ciudadanos europeos, se trataría de hacer que la profecía que anticipa la tesis de Huntington acabara negándose a sí misma, que es otra de las posibilidades que contempla el teorema de Thomas, en oposición a la profecía que se cumple a sí misma y a la que puede conducir el avance de los fundamentalismos de unas y otras culturas.

Dado que el pensamiento condiciona la acción, como señala López Pintor al considerar, al igual que se hace en este trabajo, que no existe una base objetiva que justifique el amenazante choque de civilizaciones (López Pintor, 2002:232), es preciso proponer alternativas imaginativas y objetivables a este hipotético choque. Se trataría, por un lado, de identificar las dimensiones reales del fenómeno terrorista, "en un esfuerzo honesto de investigación, colaboración y estrategia internacional". Se trataría, pues, de responder a la pregunta de hasta qué punto ciertos grupos se han convertido o participan en redes y en qué medida pueden asociarse y deslindarse de sociedades y Estados nacionales. Es algo que, desde una perspectiva metodológica, puede compartirse con los trabajos de esclarecimiento e investigación sobre tráfico de armas, drogas y prostitución. Como se ha señalado con frecuencia en los últimos tiempos, nunca en su historia el Estado Nación, que continúa todavía siendo la primera potencia, se ha visto tan desbordado por la extensión y el ritmo de la criminalidad internacionalmente originada (Held, 1989). El objetivo prioritario, siguiendo esta perspectiva, debería ser el de identificar grupos, redes y apoyos para poder contrarrestarlos y, en su caso, destruirlos. Una lógica de pensamiento y acción que difiere esencialmente de la de imaginar choques civilizatorios que amenazan la paz mundial.

Pero además, es imperativo seguir cultivando y transmitiendo a las nuevas generaciones los valores del Movimiento Ilustrado que han orientado hasta ahora la modernidad occidental, y que tienen que seguir haciéndolo en la actual fase histórica de multiculturalidad. El programa básico de la Ilustración basado en el decálogo que integran la razón, el empirismo, la ciencia, el universalismo, el progreso, el individualismo, la tolerancia, la libertad, la uniformidad de la naturaleza humana y el secularismo (Hamilton, 1992), sigue siendo tan actual y necesario para el avance de la convivencia humana como hace dos siglos, adaptándolos, eso sí, a las exigencias de la globalización. 
Los ejemplos y testimonios de personas como la jurista iraní Shirín Ebadí son un claro ejemplo de que la cultura islámica a la que no ha renunciado, como no podía ser de otro modo, esta mujer premio Nobel de la Paz, es, en principio, compatible con los valores ilustrados. Para que esta compatibilidad se cumpla es preciso defender estos valores con firmeza para que, de este modo, la amenazante tesis de Huntington acabe negándose a sí misma y las acciones de los individuos, y de la humanidad entera, se orienten por pensamientos constructivamente positivos.

Pensar una sociedad global respetuosa democráticamente con las diferentes sensibilidades culturales es, probablemente, el mejor y quizás único modo de evitar esos conflictos que continúan recordándonos que, desafortunadamente, en estos comienzos del siglo XXI no se ha alcanzado todavía el fin de la Historia tal como ha venido siendo escrita hasta ahora.

\section{REFERENCIAS BIBLIOGRÁFICAS}

BECK, U. (1998a), ¿Qué es la globalización?: falacias del globalismo, respuestas a la globalización, Barcelona, Paidós.

(1998b), La sociedad del riesgo. Hacia una nueva modernidad, Barcelona, Paidós.

CARDOSO, F.H. y E. FALLETO (1969), Dependencia y desarrollo en América Latina, México, Siglo XXI.

COHEN, R. y P. KENNEDY (2000), Global Sociology, Nueva York, Palgrave.

DÍEZ NICOLÁS, J. (2003), "Two contradictory hypotheses on globalization: Societal Convergence or Civilization Differentiation and Clash", en R.Inglehart (ed.), Human Values and Social Change. Findings from the Value Surveys, Leiden/Boston, Brill, pp. 235-263.

DÍEZ NICOLÁS, J. y R. INGLEHART (1994), Tendencias mundiales de cambio en los valores sociales y politicos, Madrid, Fundesco.

DOLFUS, O. (1999), La mundialización, Barcelona, Bellaterra.

ESMER, Y. (2003), "Is there an Islamic Civilization?", en R. Inglehart (ed.), Human values and Social Change, Leiden/Boston, Brill, pp.35-68.

FREEDOM HOUSE (2002), Freedom in the World 2002: The Democracy Gap, New York, Freedom House.

FUKUYAMA, F. (1989), “The End of History”, The National Interest, nº16/4, pp. 26-48.

GARCÍA FERRANDO, M. (2004), Globalización y Choque de Civilizaciones. Pensando nuestra Sociedad Global, Valencia, Universidad de Valencia.

GARCÍA FERRANDO, M. (coord.) (1999), Pensar nuestra sociedad. Fundamentos de Sociologia, Valencia, Tirant lo Blanch. 
GARCÍA FERRANDO, M. y A. ARIÑO (1999), Los nuevos valores de los valencianos. La Comunidad Valenciana en la Encuesta Mundial de Valores, Valencia, Tirant lo Blanch/Fundación Bancaixa.

(2001), Posmodernidad y autonomia. Los valores de los valencianos 2000, Valencia, Tirant lo Blanch.

GIDDENS, A. (1995), Modernidad e identidad del yo. El yo y la sociedad en la época contemporánea, Barcelona, Península.

(2000), Un mundo desbocado. Los efectos de la globalización en nuestras vidas, Barcelona, Paidós.

HAMILTON, P. (1992), "The Enlightenment and the birth of social sciences", en S. Hall y B. Gieben, Formations of modernity, Londres, The Open University Policy, pp.17-70.

HELD, D. (1989), "The decline of the nation state" en S. Hall y M. Jacques (eds.), New Times, Londres, Lawrence y Wishart, pp. 191-204.

HELD, D. et al. (2000), Global Transformations: Politics, Economics and Culture, Cambridge, Polity Press.

HUNTINGTON, S.P. (1993), “The Clash of Civilizations?", Foreign Affairs n $n^{\circ} 75 / 6$, pp. 28-34.

(1997), El choque de civilizaciones y la reconfiguración del orden mundial, Barcelona, Paidós.

(2004a), "The Hispanic Challenge", Foreign Policy March/April, pp. 34-41.

(2004b), ¿Quiénes somos? Los desafios a la identidad nacional estadounidense, Barcelona, Paidós.

INGLEHART, R. (1977), The Silent Revolution. Changing values and political styles among Western publics, Princeton, Princeton University Press.

(1991), El cambio cultural de las sociedades industriales avanzadas, Madrid, CIS/Siglo XXI.

(1998), Modernización y posmodernización. El cambio cultural, económico y politico en 43 sociedades, Madrid, CIS/Siglo XXI.

INGLEHART, R. (ed.) (2003), Human Values and Social Change. Findings from the Value Surveys, Leiden/Boston, Brill.

INGLEHART R. y W.E. BAKER (2000), "Modernization, cultural change and persistence of traditional values", American Sociological Review, $n^{\circ} 65 / 2$, pp. 19-51.

KLARE, M.T. (2001), “The new geography of conflict”, Foreign Affairs, mayo-junio, pp. 49-61.

LÓPEZ PINTOR, R. (2002), “¿Hay choque de civilizaciones?”, REIS, 97/02, pp.211-219. 
RIS

REVISTA INTERNACIONAL DE SOCIOLOGIA

№ 42, SEPTIEMBRE-DICIEMBRE, 2005

MANUEL GARCÍA FERRANDO

LUCAS MARÍN, A. (1986), Fundamentos de teoria sociológica, Madrid, Tecnos.

MARTÍNEZ GONZÁLEZ-TABLAS, A. (2000), Economia politica de la globalización, Barcelona, Ariel.

MERTON, R. K. (1964), Teoria y estructura sociales, México, FCE.

MOORE, B. (1966), "Global Sociology: the world as a singular system", American Journal of Sociology, $\mathrm{n}^{\circ} 71 / 5$, pp. 475-482.

NORRIS, P. e R. INGLEHART (2002), "Islamic Culture and Democracy. Testing the Clash of Civilizations Thesis", Comparative Sociology, $\mathrm{n}^{\circ} 1.3, \mathrm{pp} .235-263$.

PICÓ, J. (2003), Los años dorados de la Sociologia (1945-1975), Madrid, Alianza.

PNUD (1997), Informe sobre Desarrollo Humano, Naciones Unidas.

(2004), Informe sobre Desarrollo Humano, Naciones Unidas.

RIBAS, N. (2002), El debate sobre la globalización, Barcelona, Bellaterra.

RUIZ DE OLABUÉNAGA, J.I. (dir.) (1998), La juventud liberta. Género y estilos de vida de la juventud urbana española, Madrid, Fundación BBV.

RUSSET, B.M. et al. (2000), “Clash of civilizations, or realism and liberalism déjà vu? Some evidence”, Journal of Peace Research, $n^{\circ} 37 / 5$, pp. 583-608.

SANGUINETTI, J.J. (1977), Augusto Comte: Curso de Filosofia Positiva, Madrid, EMESA.

TORTOSA, J. Ma.(1997), "Para seguir leyendo a Wallerstein", en I. Wallerstein (coord.), El futuro de la civilización capitalista, Barcelona, Icaria, pp.103-131.

WALLERSTEIN, I. (1974), The Modern World System, Nueva York, Academic Press.

ZEITLIN, I. (1968), Teoría e ideología sociológica, Buenos Aires, Amorrortu. 